\title{
KAJIAN BIBLIKA TENTANG YESUS SEBAGAI PINTU DAN GEMBALA MENURUT YOHANES 10:1-18
}

\author{
Jonar Situmorang \\ Sekolah Tinggi Teologi Kadesi Yogyakarta \\ jonar.situmorang@gmail.com
}

\begin{abstract}
This paper examines two things, which is Jesus' statement about Himself in the Gospel of John and a statement that begins with: "I ..." (Greek: $\varepsilon \gamma \omega$ عı $=$ ego eimi). These two statements come out the phrase "I am the door" and "I am the good shepherd." Theologically, especially Christology, this emphasizes His personality as God who can be an example of leadership in the church. The purpose is to describe Jesus' declaration that $\mathrm{He}$ is the door and the Good Shepherd in John 10: 1-18 and its implications for the ministers as church leaders. The methodology in this research is descriptive analysis. As a result, the two statements of Jesus in John 10: 1-18 reflect the example of Jesus as the Good Shepherd.
\end{abstract}

Keywords: I Am the Door, The Good Shepherd, John 10:1-18

\begin{abstract}
Abstrak. Tulisan ini membahas dua hal, yaitu pernyataan Yesus tentang diri-Nya dalam Injil Yohanes dan pernyataan yang dimulai dengan: "Saya ..." (Yunani: $\varepsilon \gamma \omega \varepsilon \varepsilon \mu \mathrm{I}=$ ego eimi). Dari dua pernyataan itu terdapat ungkapan "Aku adalah pintunya" dan "Akulah gembala yang baik." Secara teologis, terutama Kristologi, ini menekankan kepribadianNya sebagai Allah yang dapat menjadi contoh kepemimpinan dalam gereja. Tujuannya adalah untuk menggambarkan pernyataan Yesus bahwa Dia adalah pintu dan gembala yang baik dalam Yohanes 10: 1-18 dan implikasinya bagi para pendeta sebagai pemimpin gereja. Metode yang digunakan adalah analisis deskriptif. Hasilnya, kedua pernyataan Yesus dalam Yohanes 10: 1-18 mencerminkan keteladanan Yesus sebagai gembala yang baik.
\end{abstract}

Kata-kata Kunci: Akulah Pintu, Gembala yang Baik, Yohanes 10:1-18

Salah satu bagian utama dalam Injil Yohanes adalah pernyataan

Yesus tentang diri-Nya sebagai roti hidup, terang dunia, pintu, gembala yang baik, kebangkitan dan hidup, jalan dan kebenaran dan hidup, dan pokok anggur yang benar. Ketujuh pernyataan ini, selalu diawali dengan kata, "Akulah...." (Yunani: $\varepsilon \gamma \omega \quad \varepsilon / \mu l=$ ego eimi), yang artinya: "Aku adalah..." Dalam setiap pernyataan, "Akulah" tercermin peran tertentu dari Yesus Kristus dalam hal mengasihi, menguatkan, menyinari, memelihara, 
memberi hidup, atau membimbing. Ucapan pernyataan Yesus ini sebagai "emphatic pronoun", ada penekanan "Aku" (Yesus), yang berarti Yesus sendiri yang mengatakan. Penekanan ini merupakan ciri penulisan Yohanes dan mempunyai makna kristologis yang besar bagi person Kristus.

Schreiner menganggap bahwa perikop ini sebagai perumpamaan yang sangat berlebihan, sebab seseorang tidak dapat berfungsi sebagai pintu bagi kawanan domba dan sekaligus sebagai gembala. Yohanes mengambil beberapa unsur khotbah itu untuk menekankan sisi pribadi dan pelayanan Yesus yang berbeda. Gambaran tentang pintu digunakan untuk menyampaikan bahwa keselamatan tersedia hanya melalui Yesus (10:9). Kawanan domba yang sejati masuk melalui pintu untuk mendapat keselamatan. (Schreiner, 2015)

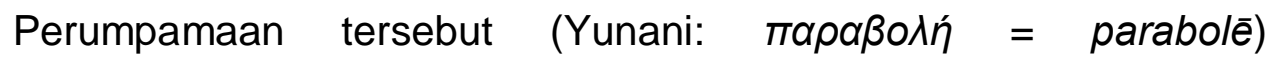
mempunyai arti luas, yaitu: amsal (Luk. 4:23), teka-teki (Mrk. 3:23), sebuah perbandingan (Mat. 13:33), sebuah kontras (Luk. 18:1-8), cerita sederhana (Luk. 13:6-9) dan cerita yang kompleks (Mat. 22:1-4). Perumpamaan sering dipandang sebagai ilustrasi karena berakar pada pemahaman kata paraballō yang secara literal berarti "melempar di sisi atau di samping". Dalam memahami suatu perumpamaan harus dicari titik perbandingan yang dimaksudkan, sehingga ada kesamaan antara gambar (cerita) dan apa yang digambarkan (Groenen, 1979). 
Dalam mengajarkan suatu perumpamaan kepada orang Farisi, Yesus mengungkapkannya dalam dua hal yang berbeda-beda dengan kiasan-kiasan biasa, yaitu: perumpamaan Yesus lebih tersembunyi artinya dan perumpamaan Yesus mengandung suatu rahasia (Bakker, 2012). Perumpamaan, dapat dikelompokkan dalam empat bagian, yaitu: similitude, parabel, alegori dan eksemplum.

Similitude berarti kemiripan. Similitude adalah sesuatu perbandingan bayangan antara objek-objek yang mempunyai kesamaan tertentu tetapi berbeda juga dalam hal-hal lain. Parabel seperti metafora yang diperluas menjadi suatu kisah singkat dan berbeda dengan fabel dalam hal pengibaratannya. Fabel menggunakan hewan, tumbuhan, dan benda lain, sedangkan parabel menggunakan manusia.

Dalam Kamus Besar Bahasa Indonesia (2008) dijelaskan bahwa alegori adalah cerita yang dipakai sebagai lambang (ibarat atau kias) perikehidupan manusia yang sebenarnya untuk mendidik (terutama moral) atau menerangkan sesuatu (gagasan, cita-cita, atau nilai kehidupan, seperti kebijakan, kesetiaan, dan kejujuran). Alegori mempunyai hubungan yang erat dengan perumpamaan. Pada dasarnya alegori merupakan metafora yang lebih luas, sedangkan perumpamaan merupakan ibarat yang lebih panjang (Susanto, 2017).

Eksemplum adalah adalah teks yang menceritakan perilaku tokoh dalam ceritanya. Contoh teks eksemplum biasanya diawali dengan 
pengenalan tokoh, kemudian peristiwa yang dialami oleh tokoh, serta ditutup dengan interpretasi yang timbul dari tokoh tersebut.

Harrison (1996) menyebut bagian dari perikop ini sebagai kiasan, yaitu gambaran yang maknanya masih harus dijelaskan. Seluk beluk gambaran itu telah dikenal benar oleh para pemelihara domba di Palestina, namun kebenaran-kebenaran rohani yang terkandung di dalamnya masih perlu dibeberkan. $\mathrm{Di}$ sini terlihat bahwa perumpamaannya dalam bentuk alegori, di mana tiap-tiap bagiannya boleh ditafsirkan. Dalam alegori ini perumpamaan yang dipakai selalu berubah untuk menjelaskan suatu segi yang baru dalam perhubungan Yesus dan para pengikut-Nya.

Drane mengatakan bahwa cara tradisional untuk mengerti perumpamaan adalah dengan menganggapnya sebagai alegori. Suatu alegori adalah uraian terperinci tentang suatu pokok, yang ditulis sedemikian rupa sehingga seakan-akan membicarakan sesuatu yang berlainan sama sekali (Drane, 2016).

Lalu apa sesungguhnya makna dari pernyataan Yesus dalam Yohanes 10:1-18 bahwa la adalah pintu dan gembala yang baik? Tulisan ini bermaksud menggali makna kedua pernyataan itu dan menemukan implikasinya bagi pelayanan dalam gereja.

\section{METODE}


Metode penelitian yang digunakan adalah kualitatif dengan studi hermeneutika. Teknik analisa datanya menggunakan analisis deskriptif terhadap teks Yohanes 10:1-18 dengan fokus pada pengakuan Yesus bahwa diri-Nya adalah pintu dan gembala yang baik. Metode ini digunakan untuk membentangkan objek penelitian dengan gambaran yang jelas sehingga pembaca dapat menemukan pemahaman seperti yang peneliti hendak singkapkan (Sari, 2019).

\section{HASIL}

\section{Maksud Pengakuan Yesus sebagai Pintu dan Gembala yang Baik}

Pada bagian ini (Yoh. 10:1-18) dua kali Yesus menyebutkan akan pengakuan-Nya sebagai pintu, yaitu: "Aku berkata kepadamu, sesungguhnya Akulah pintu ke domba-domba itu" (Yoh. 10:7), dan "Akulah pintu; barangsiapa masuk melalui Aku, ia akan selamat dan ia akan masuk dan keluar dan menemukan padang rumput" (Yoh. 10:9).

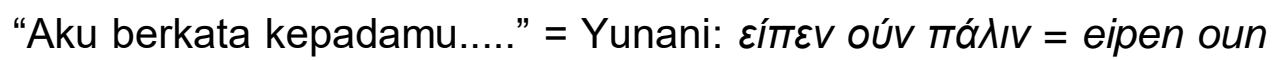

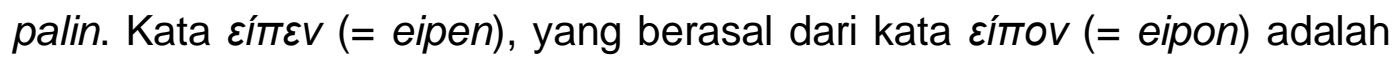
bentuk tense "aorist" (tense aorist adalah untuk menyatakan bahwa sesuatu hal pernah terjadi atau pernah dilakukan pada satu titik waktu. Kata kerja ini tidak berpatokan pada waktu lampau, sekarang, atau depan), yaitu dari kata $\lambda \varepsilon \gamma \omega$ (= lego), yang berarti: diterjemahkan: "berkata", atau "katanya". Kemudian dilanjutkan dengan kata oúv má́lIV (= oun palin); oúv (= oun) berarti: karena itu, maka, Ialu, kemudian. Kata 
mádIV (= palin) merupakan kata keterangan, yang berarti: lagi, sekali lagi (Newman, 2016).

Yesus menegaskan sekali lagi pada satu titik waktu (satu kesempatan) bahwa sesungguhnya la adalah pintu ke domba-domba itu (Yoh. 10:7). Menariknya, kata "sesungguhnya" disebutkan dua kali, yaitu $\alpha \mu \eta ́ v ~ \alpha \mu \eta ́ v ~(=$ amen amen), yang berarti: sesungguhnya sesungguhnya (Newman, 2016).

Kata di atas menunjukkan pernyataan yang tegas dan pasti bahwa Yesus adalah pintu ke domba-domba itu. Rodderbos mengatakan bahwa ini merupakan penekanan dan keterbukaan yang paling mungkin, menghilangkan semua keraguan akan maksudnya dengan mengatakan, “Aku berkata kepadamu..." (Ridderbos, 2012).

Kata $\varepsilon ı \mu$ (= eimi) berarti "adalah" (bahasa Inggris: to be), dan mempunyai tiga bentuk waktu, yaitu: present, imperfect dan futurus (Tulluan, 1992). Yesus menggunakan ungkapan "Aku adalah" atau

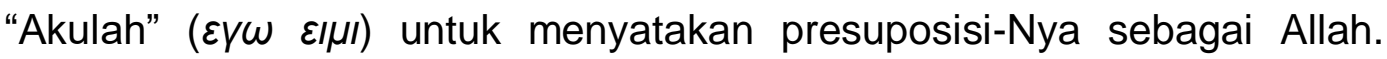
Ungkapan ini bukan sekedar ungkapan biasa sebab dengan menggunakan frasa tersebut Yesus menyatakan diri-Nya sejajar atau sama dengan Allah yang menyatakan diri-Nya kepada Musa. Dalam setiap pernyataan 'Aku adalah' menjelaskan peran tertentu dari Yesus, yaitu menguatkan, menyinari, mengakui, memelihara, memberi hidup, membimbing, dan membuat produktif. Ungkapan 'Aku adalah' digunakan dalam Perjanjian Lama sebagai penggambaran Allah (Lilo, 2019). 
Kata "pintu" (Yunani: $\theta v \rho \alpha=$ tura) memakai kata sandang, yaitu: ń (=e). Bahasa Yunani mempunyai kata sandang tertentu yang selalu ditulis di depan kata bendanya. Kata sandang tertentu hanya satu, namun mempunyai bentuk-bentuk menurut kelamin, kasus dan jumlah. Kata $\tau \omega ́ v$ (ton) artinya: ini, yang menunjuk pada pribadi Yesus sebagai pintu.

Kata sandang $\eta ́$ adalah dalam bentuk nominatif, yang dipakai dengan semua kata benda feminin berdeklensi (Wenham, 2003). Dengan demikian, kata "pintu" di sini dalam bentuk "feminin", yang berarti hanya satu pintu (Hagelberg, 2001). Pintu yang memberi masuk ke dombadomba itu hanya satu, yang tidak lain adalah pribadi Yesus.

Berarti pintulah yang memberikan jalan masuk ke domba-domba itu pada saat gembala memasuki kandang, tidak seperti pencuri-pencuri dan perampok-perampok yang tidak melalui pintu. Di sini Yesus sedang mengatakan bahwa la sendiri mewakili jalan masuk yang sah ke kandang. Dia "yang memperantarai sendiri jabatan pastoral yang benar" (Ridderbos, 2012, p. 387).

Yesus adalah "pintu ke domba-domba itu" = (= e tura ton probaton). Di sini terlihat bentuk kelamin dari kata $\tau \omega ́ v$

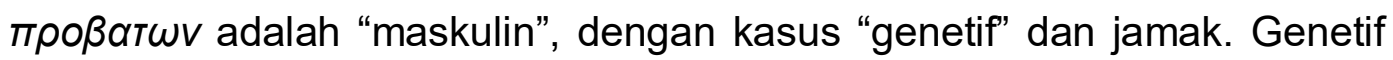
menyatakan "milik" (Tulluan, 1992, p. 14). Biasanya kasus genetif dapat diterjemahkan dalam bahasa Inggris dengan memakai "of" atau akhiran "s". Namun dalam bahasa Indonesia kasus genetif dinyatakan oleh susunan kata, bukan bentuk kata. 


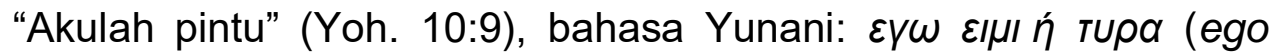
eimi e tura) $=$ Aku adalah pintu. Kalimat ini adalah kasus nominatif, yaitu kasus penamaan, karena kasus ini sering menamai atau menunjukkan topik utama dari sebuah kalimat. Penggunaan paling umum dari kasus nominatif di dalam Yunani Perjanjian Baru adalah menjadi subyek dari sebuah kalimat. Ada dua penggunaan utama kasus nominatif, yaitu sebagai subyek dan sebagai nominatif predikat.

Kata $\varepsilon \gamma \omega(=e g o)$ adalah sebagai nominatif subyek. Kasus nominatif seringkali adalah subyek dari kata kerja dalam kalimat. Kata kerjanya itu sendiri bisa muncul atau tidak muncul di dalam kalimat tersebut. Demikian juga dengan subyeknya yang berkasuskan nominatif ini bisa nampak atau tidak nampak di dalam kalimatnya. Nominatif subyek ini diikuti kata kerja equatif, yaitu $\varepsilon ı \mu$ (= eimi). Kata kerja equatif adalah kata kerja yang tidak menggambarkan sebuah tindakan melainkan sebuah keadaan atau status.

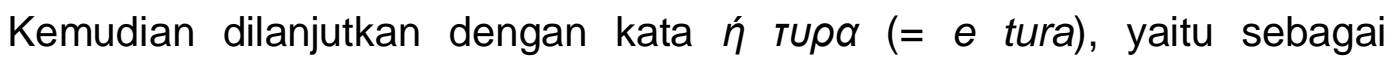
nominatif predikat, yang berfungsi serupa dengan penggunaan sebagai kasus subyek. Hanya saja nominatif predikat menggunakan sebuah kata kerja equatif, apakah itu tersurat ataupun tersirat. Di sini terlihat bahwa subyek tidak bisa bertukar kepada nominatif predikat. Artinya, bahwa hanya ada satu pintu dan tidak bisa ditukar dengan pintu lain. Pintu itu adalah Yesus, atau Yesus adalah pintu. Sebutan Yesus adalah "pintu" adalah suatu kiasan yang menceritakan kepada kita bahwa hanya Dia-lah Juruselamat yang benar (Telaumbanua, 2018). 
Berdasarkan penjelasan di atas menunjukkan bahwa keimanan kekristenan sangat tegas dengan menganut pandangan eksklusivisme. Pendekatan eksklusivisme menyatakan bahwa agama Kristen merupakan satu-satunya jalan keselamatan. Penggambaran "Akulah pintu ke dombadomba itu" memunculkan kebenaran bahwa Yesus adalah satu satunya jalan yang benar (lihat 10:8, 10:10; 14:6). Hal ini sering disebut sebagai skandal ekslusivisme Injil. Jika Alkitab ialah pernyataan diri Allah, maka hanya ada satu jalan untuk menjadi benar dengan Allah - iman dalam Kristus (lihat Kis. 4:12; I Tim. 2:5).

Dalam Kamus Gambaran Alkitab (Ryken \& Wilhoit, 2011) terdapat empat pengertian atau simbol dari pintu tersebut, yaitu:

1. Pintu tertutup menyembunyikan. Pintu tertutup secara literal mencegah agar orang-orang yang berada di luar agar tidak melihat dan mendengar apa yang sedang terjadi di dalam (1 Raj. 14:6).

2. Pintu tertutup memisahkan. Sama seperti tirai dan pintu yang tertutup dalam Kemah Suci dan Bait Allah memisahkan orang-orang yang tidak berwenang dari tempat-tempat suci itu: demikian juga pintu-pintu dalam kehidupan sehari-hari memisahkan seseorang.

3. Pintu sebagai jalan masuk rohani. Tuhan Yesus merujuk diri-Nya sendiri sebagai "pintu" (Yoh. 10:9). Dalam konteks tersebut ini tentunya adalah pintu bagi domba-domba dan dengan demikian sebagai pintu gerbang atau jalan masuk kepada keselamatan. 
4. Pintu sebagai peluang bagi Injil. Paulus memakai gambaran pintu tiga kali secara kiasan untuk menyatakan peluang-peluang yang tersedia bagi tersebarnya Injil. Gambaran ini mengandung ide bahwa pintu terbuka membuka suatu kemungkinan.

Pengertian "pintu" juga merupakan metafora dari kesempatan yang melaluinya pendosa didamaikan dengan Allah (Hos. 2:15; Mat. 7:13-14; Luk. 13:24; Yoh. 10:1-9; Kis. 14:27), kesempatan untuk mengabarkan Injil (Kol. 4:3; Why. 3:8), kedatangan Kristus untuk kedua kalinya (Mat. 24:33; Mrk. 13:29; Yak. 5:9), ketaatan yang menghantar orang percaya menikmati kehadiran Kristus dalam hidup mereka (Why. 3:20).

Ungkapan Yesus yang berkata, "Aku berdiri di muka pintu dan mengetok" (Why. 3:20) diperbandingkan oleh Hagelberg (1997) dengan tuntutan pejabat-pejabat Roma yang menuntut dengan kekerasan untuk masuk rumah orang. Di sini kata "pintu" menunjukkan "hati" manusia. Yesus hendak masuk ke pintu hati manusia dengan sabar menunggu supaya manusia membukakan hatinya dan mempersilakan Yesus masuk ke dalam. Kistemaker menanggapi ungkapan Yesus ini demikian:

la terus mengetuk agar memperoleh perhatian, sehingga tidak ada yang bisa berkata Tuhan tidak memperingatkan mereka. la memanggil mereka secara pribadi dengan terus mengetuk pintu hati seolah-olah si tuan rumah sedang tidur. Yang ditekankan adalah tanggung jawab manusia untuk melangkah ke pintu dan menjawab ketukan ini (Kistemaker, 2009, pp. 186-187).

Sebagai pintu, Yesus membebaskan orang-orang berdosa dari perbudakan dan memimpin mereka menuju kemerdekaan. Mereka 
memiliki keselamatan! Kata "diselamatkan" memiliki arti "dibebaskan dengan aman dan pasti" (Wiersbe, 2009, p. 163). Yesuslah pintu kepada keselamatan dan kebahagiaan yang kekal. Di dalam Dia ada berkat kehidupan, ke mana pun mereka pergi dalam mengiring Yesus akan mengalami pemeliharaan-Nya.

“.... Akulah pintu ke domba-domba itu” (Yoh. 10:7); tampaknya berarti pintu yang memberikan jalan masuk ke domba-domba itu dan di mana gembala, tidak seperti pencuri-pencuri dan perampok-perampok, memasuki kandang. Yesus sedang mengatakan bahwa la sendiri mewakili jalan masuk yang sah ke kandang (Ridderbos, 2012). Jalan keselamatan hanya di dalam satu nama, yaitu: Tuhan Yesus Kristus (Kis. 4:12).

Bagian kedua dari Yohanes 10:1-18 ini adalah pengakuan atau pernyataan Yesus sebagai Gembala yang baik."Akulah gembala yang

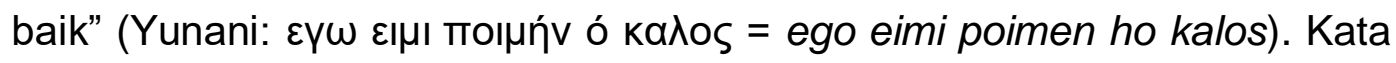

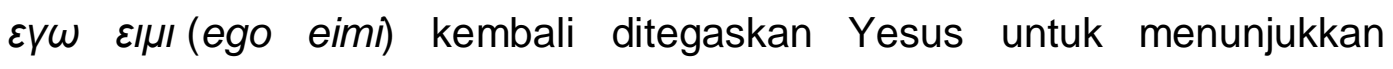
keterkaitannya dengan Yahweh. Ini menegaskan bahwa diri-Nya adalah Allah.

Seorang gembala yang sungguh-sungguh, bukan dia yang memilih jabatannya, melainkan dia dipilih untuk jabatannya, sebab ia taat pada panggilan Ilahi. Seorang gembala menerima perintah dari surga dan harus melakukannya, apapun yang akan terjadi. Pada akhirnya dia akan memberikan pertanggunganjawabannya kepada Allah karena itu Allahlah 
yang harus dilayaninya dengan bersungguh-sungguh hari demi hari (Telaumbanua, 2018).

Ajaran mengenai Yesus sebagai gembala yang baik menunjukkan perbedaannya dengan gembala palsu atau gembala upahan. Gembala yang baik memberikan nyawanya bagi domba-dombanya. Kata "memberikan nyawanya" dalam bahasa aslinya (Yunani) adalah $\psi u x \eta ́ v$ аи́тои́ тıӨクбIV (psuchen autou tithesin). Kata "memberikan" (Yunani: IIOnoIV = tithesin) berarti: menyerahkan (Susanto, 2017, p. 546), lays down = berbaring (Green, 1986, p. 829). Kata "lays down" di sini bermakna berbaring sampai rebah, yang menunjukkan tidak berdaya lagi karena sudah mati. Hal ini terbukti dengan kata berikutnya: $u \cup x \eta ́ v$ (psuchen), yang berarti: nyawa atau jiwa (Inggris: soul). Karena itu, Yesus mengundang umat manusia untuk datang kepada-Nya dan belajar kepada-Nya (Mat. 11:28-29).

Bukti dan tanda gembala yang baik adalah la masuk ke kandang melalui pintu untuk menemui domba-domba-Nya (Yoh. 10:2). Kandangkandang domba di Palestina mempunyai satu pintu saja yang dikawal oleh gembalanya. Sang gembala akan memanggil domba-dombanya untuk masuk dan keluar dari kandang itu. Michael Eaton menjelaskan bagaimana penggembalaan pada masa itu:

Pada malam hari ada banyak domba yang menjadi milik beberapa gembala yang berbeda. Ada pintu gerbang dan penjaga pintu yang mengawasi agar tidak ada pencuri yang masuk ke dalam tanah berpagar itu. Pada pagi hari, gembala itu akan datang dan memanggil domba-dombanya. la memberi nama untuk masing- 
masing domba. Ada banyak gembala di sana, tetapi suara masingmasing gembala bisa diketahui dan dikenali oleh dombanya sendiri saja. Ketika ia memanggil mereka, sering kali dengan menggunakan nama mereka, mereka akan keluar dari tanah berpagar itu dan gembala itu akan berjalan pergi diiringi dombadomba itu. (Eaton, 2008, p. 151)

Yesus menyebut dirinya sebagai "Gembala yang Baik". Lawan kata "yang baik" adalah "pandir" atau "yang jahat". Dalam bahasa Yunani, kata "yang baik" adalah $\kappa a \lambda o s$ (kalos) berarti mulia dan teladan. Yesus sebagai gembala yang baik adalah pribadi yang mulia dan memberi teladan kepada manusia. Itulah sebabnya la berkata, "Belajarlah kepada-Ku....." (Mat. 11:28-29), karena Yesus lemah lembut dan penuh kasih. Adapun kriteria gembala yang baik, yang disebutkan dalam Yohanes 10:1-18 adalah:

Pertama, masuk melalui pintu mendatangi domba-dombanya (Yoh. 1:2). Hal ini menunjukkan bahwa gembala itu menyayangi dombanya. Dia datang melakukan kebaikan bagi domba-dombanya, untuk membalut yang luka dan menguatkan yang sakit (Yeh. 34:16). Domba membutuhkan perawatan manusia dan sebagai balasannya domba memberikan manfaat bagi manusia (1 Kor. 9:7) yaitu menghasilkan bahan pakaian dan makanan bagi mereka yang telah melindunginya.

Kedua, domba-domba mendengarkan suaranya (Yoh. 10:3). Begitu juga gembala mengenal suara domba-dombanya. Ketika nama-nama domba itu dipanggil sang gembala, mereka menurut dengan sukacita. Mengapa bisa demikian? Karena ada hubungan kedekatan antara domba 
dan gembala; ada respon khusus dan lebih terhadap domba-domba itu (bnd. Mzm. 23:2).

Ketiga, gembala memanggil domba-dombanya menurut namanya dan menuntunnya keluar (Yoh. 10:4). Domba hanya mau mendengar dan menuruti gembalanya. Ketika nama domba itu dipanggil, langsung saja direspon dan mendekati si gembala. Sebaliknya, kalau yang memanggilnya orang asing, si domba tidak mengikutinya dan bahkan melarikan diri (Yoh. 10:5) karena merasa takut.

Gembala di Timur Tengah biasanya berdiri di pintu kandang ketika domba-domba masuk keluar dan melewati dia satu demi satu sementara ia menghitung dan memeriksa mereka. la adalah pintu bagi mereka kepada keselamatan, kemerdekaan dan kecukupan bagi kekurangan (Tenney, 2003). Sesudah dipanggil keluar dari kandang, maka si domba itu dituntun keluar ke padang rumput yang hijau dan ke air yang tenang. Sang gembala sudah tahu di mana letak padang rumput yang hijau.

Keempat, gembala itu berjalan di depan dan domba-domba mengikutinya (Yoh. 10:4). Domba itu mengikuti si gembala karena mereka mengenal suara gembalanya. Kalau suara yang lain, domba-domba itu akan lari karena merasa tidak mengenal dan takut. Berjalan di depan ini adalah untuk mencegah bahaya apa pun yang mungkin menghadang domba-domba itu, dan karena sudah terbiasa dengan cara itu, mereka pun mengikutinya sehingga aman (Henry, 2010). Hal ini juga menggambarkan suatu keteladanan kepemimpinan dalam hal kerohanian. 
Kasih Allah ditunjukkan dengan mengawasi, menjagai domba gembalaan-Nya siang dan malam. Sesungguhnya bahwa tidak terlelap dan tertidur penjaga Israel (Mzm. 121:4). Tuhan melihat ke bawah dari surga-Nya yang kudus (Mzm. 14:2a). Ketegasan-Nya ditunjukkan dengan kecaman dan ancaman terhadap yang mencerai beraikan. Zaman modern ditandai dengan sikap arogansi dan individualisme. Kemunduran adalah salah satu segi dari situasi itu. Kecaman Allah terhadap gembala dalam ayat di atas adalah sebuah fakta terjadi kemunduran sikap, motivasi, dan perilaku penggembalaan. Perlu disadari kemunduran motivasi penggembalaan terkadang disebabkan oleh faktor-faktor internal, tetapi juga bisa disebabkan oleh faktor eksternal yang bersangkutan (Mulyono, 2017).

\section{KESIMPULAN}

Maksud dari pengakuan Yesus sebagai pintu adalah sebagai pintu menuju keselamatan. Hanya satu jalan menuju surga yang kekal untuk memperoleh hidup yang kekal, yaitu melalui satu pintu di dalam nama Yesus Kristus. Tidak ada kompromi terhadap pengakuan Yesus ini

Pembelajaran akan pengakuan Yesus sebagai pintu ini dalam penggembalaan adalah:

1. Keselamatan bersifat eksklusif. Pandangan ini menyatakan bahwa jika

Yesus Kristus secara unik adalah kebenaran dan satu-satunya jalan keselamatan bagi umat manusia, itu berarti agama-agama lain bukan 
jalan keselamatan (Situmorang, 2013). Model keimanan kekristenan bersifat eksklusif, di mana dengan tegas mengatakan bahwa hanya ada satu nama yang menyelamat manusia, yaitu nama Tuhan Yesus Kristus (Kis. 4:12).

2. Pengajaran. Seorang gembala sidang harus kokoh dalam hal pengajaran. Pengajaran-pengajaran yang ditinggalkan kedua belas rasul oleh gereja-gereja di abad kedua dijadikan petunjuk serta prinsip dan pola penggembalaan. Rothlisberger menulis,

Di dalam gereja Evangelis (Injli) khotbah itu mempunyai tempat yang sentral karena tugas gereja yang utama ialah mengabarkan firman Tuhan di dalam dunia. Biar pun kesaksian gereja tidak terdiri atas perkataan saja (kerygma dan didache), melainkan berbentuk persekutuan (koinonia) dan pelayanan (diakonia) juga, namun pekabaran Injil adalah tugas yang utama daripada saksi-saksi Kristus." (Rothlisberger, 2015, p. 5).

Dengan pengajaran yang sehat, jemaat akan bertumbuh dengan sehat. Seorang gembala mempunyai perlengkapan dalam penggembalaannya. Salah satu peralatannya yang utama adalah tongkat. Musa sebagai seorang gembala, selalu siap sedia tongkat di tangannya. Damazio (1993, p. 99) memaknai kata "tongkat" ini secara rohani, dengan mengatakan: "Kemajuan spiritual gereja tergantung pada para pemimpin rohani yang cakap menjebol kendala-kendala yang ada" (bnd. Kel. 14:15; 4:1-3). Orang dengan tongkat adalah kunci menggerakkan umat Allah maju. 


\section{DAFTAR PUSTAKA}

Bakker, D. F. L. (2012). Sejarah kerajaan Allah 1. Jakarta: BPK Gunung Mulia.

Damazio, F. (1993). Kunci-kunci Efektif bagi Kepemimpinan yang Sukses. Jakarta: Harvest Publication House.

Departemen Pendidikan Indonesia. (2008). Kamus Besar Bahasa Indonesia. Jakarta: Balai Pustaka.

Drane, J. (2016). Memahami Perjanjian Baru. Jakarta: BPK Gunung Mulia.

Eaton, M. (2008). Jesus of the Gospels: kronologi kisah Yesus menurut empat Injil. Yogyakarta: Andi.

Green, J. P. (1986). The Interlinear Bible: Hebrew-Greek-English. Michigan: Baker Book House.

Groenen, C. (1979). Peristiwa Yesus: Teologi Alkitabiah tentang segala sesuatu yang dikerjakan Yesus. Yogyakarta: Yayasan Kanisius.

Hagelberg, D. (1997). Tafsiran Kitab Wahyu dari Bahasa Yunani: wahyu Yesus Kristus. Yogyakarta: Yayasan Andi.

Hagelberg, D. (2001). Tafsiran injil Yohanes. Yogyakarta: Yayasan Andi.

Harrison, E. F. (1996). InjilYohanes. Jakarta: BPK Gunung Mulia.

Henry, M. 1662-1714. (2010). Tafsiran Injil Yohanes 1-11, 12-21. Surabaya: Momentum.

Kistemaker, S. J. (2009). Perumpamaan Tuhan Yesus. Malang: SAAT.

Lilo, D. D. (2019). Presuposisi dan Metode Yesus dalam Menyampaikan Pendapat: Sebuah Pedoman bagi Para Akademisi. BIA': Jurnal Teologi Dan Pendidikan Kristen Kontekstual. https://doi.org/10.34307/b.v2i1.86

Mulyono, S. (2017). Integrasi Pelayanan Konseling dan Misi Kristen: Suatu Upaya Pendekatan Terapan dalam Konseling. Jurnal Bina Muda Wirawan-GO, 1(2).

Newman, B. M. (2016). Kamus Yunani - Indonesia: Untuk Perjanjian Baru (22nd ed.). Jakarta: BPK Gunung Mulia. 
Ridderbos, H. N. (2012). Injil Yohanes. Surabaya: Momentum.

Rothlisberger, H. (2015). Homiletika: ilmu berkhotbah. Jakarta: BPK Gunung Mulia.

Ryken, L., \& Wilhoit, J. C. (2011). Kamus Gambaran Alkitab. Surabaya: Momentum.

Sari, D. N. (2019). Upaya Preventif Guru Kristen dalam Menghadapi Degradasi Moral Anak. Visio Dei: Jurnal Teologi Kristen, 1(1), 79100.

Schreiner, T. R. (2015). New Testament Theology. Yogyakarta: Penerbit Andi.

Situmorang, J. (2013). Kristologi. Yogyakarta: Andi.

Susanto, H. (2017). Hermeneutik. Malang: SAAT.

Telaumbanua, E. (2018). Pemimpin sebagai Gembala Berdasarkan Injil Yohanes 10:1-18. Jurnal Bijak, 2(1), 66-109.

Tenney, M. C. (2003). Injil Iman : suatu telaah naskah Injil Yohanes secara analitis. Malang: Gandum Mas.

Tulluan, O. (1992). Introduksi Perjanjian Baru. Batu: Departemen Literatur YPPII.

Wenham, J. W. (2003). Bahasa Yunani Koine. Malang: SAAT.

Wiersbe, W. W. (2009). Hidup Di Dalam Kristus: mengenal sang Juru Selamat yang hidup lebih dalam lagi. Bandung: Yayasan Kalam Hidup. 